\title{
MEIOS CONSENSUAIS DE RESOLUÇÃO DE CONFLITOS: CONCILIAÇÃO E MEDIAÇÃO
}

Bruna Mayara da Silva, Lorraine Cristina Quirino, Yasmin Batistela Chrisostomo e Flávia Caroline Marsola.

Universidade do Oeste Paulista - UNOESTE, Presidente Prudente, SP. E-mail: bhonorato.bh1@gmail.com

\section{RESUMO}

O presente trabalho tem o objetivo de demonstrar que boa parte do número de demandas judiciais que abarrotam o Poder Judiciário poderiam ser solucionadas por modos alternativos de solução de conflitos, não chegando à jurisdição. Conclui-se que o Código de Processo Civil e o Conselho Nacional de Justiça por meio da Resolução 125/2010, justamente pensando em melhor solucionar os conflitos, em conformidade com a Constituição Federal de 1988, incentivam a conciliação e a mediação como política judiciária adequada e efetiva de solução de litígios, visando à harmonia social e o restabelecimento do sentimento de justiça na sociedade. Para a elaboração desse artigo foi utilizado o método hipotético dedutivo.

Palavras- chaves: Conciliação. Mediação. Justiça. Solução de Conflitos. Resolução 125/2010.

\section{CONSENSUS MEANS OF SETTLEMENT OF CONFLICTS: CONCILIATION AND MEDIATION}

\begin{abstract}
This paper aims to demonstrate that a large part of the number of lawsuits that overwhelm the Judiciary could be solved by alternative ways of solving conflicts, not reaching the jurisdiction. It is concluded that the Code of Civil Procedure and the National Council of Justice, through Resolution $125 / 2010$, precisely in order to better resolve the conflicts, in accordance with the 1988 Federal Constitution, encourage conciliation and mediation as an adequate judicial policy and effective solution of litigation, aiming at social harmony and the reestablishment of the sense of justice in society. The hypothetical deductive method was used for the elaboration of this article.
\end{abstract}

Keywords: Conciliation. Mediation. Justice. Conflict Resolution. Resolution 125/2010. 


\section{INTRODUÇÃO:}

O Novo Código de Processo Civil estando em sintonia com a Constituição Federal de 1988, estabelece que o Estado Democrático promoverá a solução consensual dos conflitos (GUERRERO, 2015).

Nesta linha de pensamento, o Conselho Nacional de Justiça, editou a Resolução no 125/2010 estabelecendo política judiciária para a criação de meios adequados e efetivos de resolução de litígios de forma pacífica, beneficiando a população em geral, ao preservar vínculos entre pessoas.

O objetivo desse artigo é demonstrar que a Resolução 125/2010 juntamente com o Código de Processo Civil propagam e incentivam a mediação e conciliação em todas as regiões do país, por meio da instalação de centros apropriados para tais práticas, capacitando seus operadores e mostrando à sociedade que esses meios consensuais de resolução de conflitos são apropriados para determinados litígios, por meio dos quais as partes compreendem a importância de respeitar os valores sociais e morais para entrarem em consenso, e a desnecessidade de utilizar o Judiciário para resolver demandas que podem ser solucionadas de forma mais célere, eficaz e menos burocrática.

\section{METODOLOGIA}

O presente artigo foi orientado por pesquisas bibliográficas, leituras, fichamentos, bem como por leis e resoluções. O método utilizado foi o hipotético-dedutivo, ou seja, partindo da análise geral para o particular.

\section{DISCUSSÃO}

Atualmente no Brasil, não há a cultura de resolver conflitos de forma amigável, mas a frequente utilização do Poder Judiciário, ocasionando enorme número de ações judiciais diariamente propostas, com demandas repetitivas e desgastantes; comprometendo a integridade da máquina judiciária perante a sociedade e acabando por muitas vezes piorando os conflitos já instalados e consequentemente sobrecarregando o serviço público.

Neste contexto, a Constituição Federal em seu artigo 5, inciso, XXXV, garante o direito de apreciação pelo poder judiciário, sempre que houver lesão ou ameaça ao direito de um ser humano, o que não significa que sempre que houver uma controvérsia, o cidadão deva ingressar em juízo para satisfazer seu interesse, pois o próprio preâmbulo da Carta Maior realça a busca de solução pacífica de controvérsias, o que é exposto pelo doutrinador Guerrero (2017, p. 28):

$\mathrm{Na}$ Constituição Federal em vigor, os métodos adequados ou alternativos de solução de controvérsias, ou MASCs, retomam papel de destaque para aplicação no âmbito do direito interno e privado.[..] não se pode esquecer de que o preâmbulo da Constituição indica ser o Brasil um Estado Democrático e comprometido "na ordem interna e internacional, com a solução pacífica das controvérsias". Em termos de legislação infraconstitucional, são diversas as previsões para utilização e efetivação dos métodos de solução de controvérsias.[...] lei de arbitragem [...] Resolução no 125 do CNJ, de 29 de novembro de 2010.

O Código de Processo Civil de 1973 já previa meios alternativos de solução de conflitos, mas devido a pouca exploração, divulgação, e até mesmo por desconhecimento da população, não eram utilizados de forma efetiva. Porém, o Novo Código de Processo Civil traz o intuito de modificar esse cenário com os institutos da Conciliação e Mediação, que podem proporcionar a resolução dos conflitos de forma amigável, o que muitas vezes deixa de ser incentivado.

Inicialmente, o Código de Processo Civil em seu artigo 3ㅇ diz que a conciliação, a mediação e outros métodos de resolução de conflitos devem ser incentivados por juízes, advogados, Ministério Público etc. Assim, todos os sujeitos do processo devem se empenhar em solucionar de 
forma consensual os conflitos, através de meios que além de desafogar o Judiciário também ajudam na pacificação e celeridade do processo.

Segundo Gonçalves (2017, p. 253) e Didier (2016, p. 274), respectivamente, a conciliação e a mediação podem ocorrer a qualquer momento até mesmo antes de existir o processo jurisdicional, sendo o conciliador e o mediador importantes auxiliares da justiça, vejamos:

Há duas providências determinadas pelo legislador, que visam diretamente a facilitar e a favorecer a autocomposição. A primeira delas é a instituição de uma audiência de tentativa de conciliação já no inicio do procedimento comum, antes que o réu tenha oportunidade de oferecer resposta, pois, depois dela, pode haver um recrudescimento do conflito, que dificultará a conciliação.[..] A segunda é a inclusão de mediadores e conciliadores como auxiliares da justiça.

A mediação e a conciliação podem ocorrer extrajudicialmente ou judicialmente, quando ja existente o processo jurisdicional. Neste ultimo caso, o mediador e o conciliador são auxiliares da justiça. Esta qualificação é importante, pois a eles devem ser aplicadas as regras relativas a esse tipo de sujeito processual, inclusive em relação ao impedimento e à suspeição, arts. 148 ,Il, 170 e 173,II, CPC.

Em ato contínuo, na Seção $V$ do Capítulo $V$ o legislador, estabeleceu que os tribunais criarão centros judiciários de resolução de conflitos, que serão responsáveis pelas audiências de conciliação e mediação, bem como por programas destinados a autocomposição, conforme artigo 165 do Código de Processo Civil.

No artigo 334 do mesmo código, estabeleceu-se que a petição inicial, deve atender aos requisitos essenciais e caso não haja improcedência liminar do pedido, o juiz designará a audiência de conciliação e de mediação, sendo o réu citado com, pelo menos, vinte dias de antecedência.

O não comparecimento e a ausência de justificativa aceitável das partes na audiência de conciliação e mediação é considerado ato atentatório à dignidade da justiça, estipulando-se multa de até dois por cento da vantagem econômica pretendida ou do valor da causa, revertida em favor da União ou do Estado, tendo esta natureza punitiva, visando evitar o descomprometimento das partes com a tentativa de solução consensual do conflito.

De acordo com Theodoro (2018, p. 458), a conciliação e a mediação são métodos que vem ganhando espaço nos ordenamentos jurídicos, vejamos:

A conciliação e a mediação são métodos alternativos de resolução de conflitos, que vêm ganhando força nos ordenamentos jurídicos modernos, pois buscam retirar do Poder Judiciário a exclusividade na composição das lides. Ninguém melhor do que as próprias partes para alcançar soluções mais satisfatórias para suas contendas, chegando à autocomposição, por meio da alternative dispute resolution (ADR), na linguagem do direito norte-americano.

O ilustre Didier Jr. (2016) define essas duas técnicas de autocomposição de conflitos como uma forma por meio da qual um terceiro auxilia as partes a chegarem a um resultado.

Assim, temos que a conciliação e a mediação amplamente incentivadas no ordenamento jurídico brasileiro são institutos que apesar de terem objetivo comum, qual seja, a resolução amigável de conflitos, possuem diferenças em alguns aspectos.

De acordo com Scavone (2016), na conciliação o conciliador atua na busca de uma resolução para o conflito sem impor compulsoriamente sua sugestão e, na mediação, o mediador apenas auxilia sem interferir na decisão dos envolvidos facilitado a solução do litígio.

Entretanto, "a mediação é adequada para vínculos de caráter mais permanente ou ao menos mais prolongados. E a conciliação, para vínculos que decorrem do litigio propriamente, e não têm caráter de permanência" (GONÇALVES, 2017, p.255).

Desse modo, os litigantes antes de escolherem qual dos dois métodos iram utilizar para a resolução do conflito, devem analisar a relação que anteriormente possuía com o seu oponente. 
Tendo em vista o objetivo de promoção de ações de incentivo à autocomposição de conflitos visando a paz e harmonia na sociedade, o Conselho Nacional de Justiça, em agosto de 2006, implantou um movimento pela conciliação, promovendo a busca pela solução de litígios mediando construção de acordos, lançando a Semana Nacional da Conciliação, abrangendo todos os tribunais do país.

Assim, foi editada a resolução no 125/2010 que preceitua como política judiciária meio pacífico de solução de litígios, beneficiando a população em geral, por ajudar a preservar os vínculos entre pessoas, ser mais acessível e também por beneficiar o Judiciário, diminuindo o número de ações, desnecessárias, onde com um trabalho adequado, um olhar sobre a situação, e indicando os caminhos, as próprias partes chegariam a solução do conflito, restaurando a confiança na justiça.

Além da Resolução 125/2010, o CNJ também publicou a Recomendação n. 50/2014 com o objetivo de estimular e incentivar os tribunais na adoção das técnicas consensuais de resolução de conflitos:

\begin{abstract}
A resolução 125/2010 é um importante ato normativo, pois " [...]é uma necessidade consolidar uma politica publica permanente de incentivo e aperfeiçoamento dos mecanismos consensuais de solução de litígios. Sendo a conciliação e mediação instrumentos efetivos de pacificação social, solução e prevenção de litígios, a sua apropriada disciplina em programas ja implementados no país tem reduzido a excessiva judicialização dos conflitos de interesses, a quantidade de recursos e de execução de sentença. (DIDIER, 2016, p. 273)
\end{abstract}

Dessa forma, as práticas alternativas de solução de conflitos de forma pacífica, têm sido bastante criticadas por advogados, que olham para a conciliação e mediação com desconfiança e temem pela perda de mercado de trabalho, sem contar o temor do próprio Poder Judiciário, que possui servidores capacitados para exercer a nova técnica de solução de conflitos.

Neste contexto, pondera Bacellar (2016, p. 84), que "os próprios advogados e magistrados, em sua maioria, valorizam mais a atuação adversarial do que a atuação consensual".

Devido a essa desconfiança e falta de incentivo, cada vez mais os mediadores e conciliadores devem receber capacitação teórica e prática, para que auxilie de forma imparcial e condizente com a realidade fática apresentada. Não se exige que o mediador e conciliador atuem para solucionar o litígio, como se fosse um especialista no assunto, mas espera-se que seja um profissional apto a exercer o seu papel de incentivador de resolução amigável de conflitos para ajudar as partes a chegarem ao acordo ideal.

O Código de Processo Civil em seu artigo 165 e seguintes, apresenta como capacitação para os operadores da mediação e conciliação treinamentos, assim a técnica processual e a técnica dos MASCs só poderão ser bem aplicadas por indivíduos que efetivamente as conheçam, que saibam seus detalhes e procedimentos de maneira correta (GUERRERO, 2015).

Vários são os que pensam e apoiam essa posição de capacitar de forma especifica aqueles que irão ser mediadores e conciliadores, nesta linha de pensamento encontra-se o doutrinador Gonçalves (2017, p. 258):

Não se exigirá do conciliador ou do mediador conhecimentos jurídicos. O que se exige dele é que tenha capacitação mínima, obtida com um curso ministrado por entidade credenciada, cujo currículo terá os seus parâmetros definidos pelo Conselho Nacional de Justiça em conjunto com o Ministério da Justiça (no caso do mediador, a capacitação vem explicitada no art. 11 da Lei n. 13.140/2015)

Com a devida capacitação, os mediadores e conciliadores devem obter um certificado e um cadastro, que afirma estarem aptos para exercer tal atividade, por meio de inscrição no cadastro nacional e no cadastro do Tribunal de Justiça ou Tribunal Regional Federal (GONÇALVES, 2017).

Sendo assim, os mediadores e os conciliadores devem agir de forma imparcial, caso 
contrário, poderão ser impedidos de exercer suas funções, de acordo com o artigo 170 do CPC, uma vez que estão sujeitos às causas de impedimento aplicada aos juízes, neste contexto, pondera Gonçalves (2017, p. 260) que "devem ser a eles aplicadas as mesmas causas de impedimento do juiz, previstas no art. 144 do CPC, que sejam pertinentes à atividade deles".

Logo, no exercício da mediação e da conciliação, seus operadores devem se atentar para a complexidade do caso, pois muitas vezes, os conflitos expostos não são os que causam efetivamente o mal estar, a perplexidade e a insatisfação da parte, e se não forem conhecidas a fundo os motivos corretos, pode-se piorar a lide já instalada.

Frisa-se que o incentivo a conciliação e mediação não tem como objetivo inibir ou acabar com o papel imprescindível do Poder Judiciário solucionando conflitos sociais, apenas visa resolver tais conflitos de forma harmônica, onde as partes cheguem juntas e por si só a um acordo.

A autocomposição não deve ser vista como uma forma de diminuição do numero de causas que tramitam no judiciário ou como técnica de aceleração dos processos. São outros os valores subjacentes à politica de tratamento adequado dos conflitos juridicos: 0 incentivo à participação do individuo na elaboração da norma juridica que regulara o seu caso e o respeito a sua liberdade. (DIDIER, 2016, p. 280)

Quanto a remuneração desses pacificadores, Gonçalves (2017, p.259), menciona que "o art. 169 estabelece que o conciliador e o mediador fazem jus à remuneração, conforme tabela fixada pelos tribunais, observados os parâmetros estabelecidos pelo Conselho Nacional de Justiça".

Por fim, são vários os princípios que regulam a conciliação e a mediação, de acordo com o artigo 166 do CPC, dentre eles estão a confidencialidade onde se predomina o sigilo das informações apuradas na sessão; a imparcialidade que assegura que valores ou conceitos pessoais interfiram no meio de execução do trabalho; independência e autonomia que diz ser os mediadores e conciliadores livres, podendo recusar, suspender ou interromper a sessão se ausentes as condições necessárias para seu bom desenvolvimento; respeito à ordem publica e às leis vigentes; oralidade e informalidade, pois esses meios alternativos não tem todos os trâmites e procedimentos legais do judiciário.

\section{CONCLUSÃO}

O Código de Processo Civil e o Conselho Nacional de Justiça, com o intuito de diminuir o excesso de ações, vêm incentivando os meios alternativos de solução de conflitos, especialmente a mediação e a conciliação. Ademias divulga a existência dos institutos, atuando na capacitação de seus membros, tornando tais meios de solução de conflitos reais e eficazes, de modo a promover a harmonia na sociedade, o acesso à justiça e a resolução de conflitos de forma pacífica preservando as relações entre as partes resultando na redução de custos para as mesmas.

Cumpre salientar, que as partes são livres para escolherem o método consensual que desejam utilizar para solucionar o conflito e que também exercem papel decisório para se chegar ou não a um consenso. A tarefa dos mediadores e conciliadores é apenas entender o conflito e mapear as possíveis soluções, devendo ser imparciais e buscar o bem estar das partes, conduzindo a situação com informalidade, sigilo e confidencialidade.

Dessa maneira, fica evidente a tarefa de conscientização dos cidadãos e dos profissionais do ramo jurídico de que o acionamento do Estado-juiz nem sempre é o melhor caminho. 0 incentivo a tais mecanismos alternativos de resolução de conflitos não pode deixar de ser exercitado. É necessário que antes do início do processo haja a tentativa de solução pacífica e, apenas após a frustação de tal acordo, houvesse a procura pelo Judiciário.

\section{REFERÊNCIAS}

BACELLAR, R. P. Mediação e arbitragem. 2 ed. São Paulo: Saraiva, 2016. 
BRASIL. Código de Processo Civil. Lei 13.105, 16 de março de 2015. Disponível em: <http://www.planalto.gov.br/ccivll_03/_Ato2015-2018/2015/Lei/L13105.htm> Acesso em: 03 jul. 2018.

BRASIL. Conselho Nacional de Justiça. Resolução 125/2010. Disponível em:<http:// www.cnj.jus.br///images/atos_normativos/resolucao/resolucao_125_29112010_1103201616283 9.pdf> Acesso em: 03 jul.2018.

BRASIL. Constituição (1988). Constituição da República Federativa do Brasil. Brasília: Senado Federal, 1988.

DIDIER, J.F. Curso de direito processual civil: introdução ao direito processual civil, parte geral e processo de conhecimento. 18 ed. Salvador: Jus Podivm, 2016.

GONÇALVES, M.V.R. Novo curso de direito processual civil, volume 1: teoria geral e processo de conhecimento. 14 ed. São Paulo: Saraiva, 2017.

GUERRERO. L. F. Os métodos de solução de conflitos e o processo civil. São Paulo: Atlas, 2015.

THEODORO, J.H. Curso de direito processual civil. 59 ed. Rio de Janeiro: Forense, 2018.

SCAVONE, L. A.J. Manual de arbitragem: mediação e conciliação. 7 ed. Rio de Janeiro: Forense, 2016. 